\title{
Fecundity and survival of Carpophilus hemipterus (Linnaeus, 1758) (Coleoptera: Nitidulidae) on alternative hosts
}

\section{Seun Olaitan Oladipupo*, Chris Oluwakayode Adedire and Olahire Ayo Gbaye}

Department of Biology, Federal University of Technology P.M.B. 704 Akure, Nigeria.*Email: seun_oladipupo@yahoo.com.

\begin{abstract}
The tendency of the dried fruit beetle Carpophilus hemipterus (Linnaeus, 1758) (Coleoptera: Nitidulidae) to occur as pests in stores and fields has necessitated investigations on its fecundity and survival on some alternative food hosts such as groundnut, cocoa, cowpea and rice. Two copulating pairs of the adult beetle were introduced on fifty grammes of each food substrate in a no choice test at $28^{\circ} \mathrm{C} \pm 3^{\circ} \mathrm{C}$ and relative humidity of $75 \% \pm 5 \%$. The number of eggs laid, emerged larvae, and enclosed adults were recorded. Weight loss of the food substrates was also recorded. Analysis of variance was performed on the data generated. Kaplan Meier analysis was carried out to determine the beetle survival rate on each host. Fewer eggs were deposited on rice compared to the other hosts; however, there was no significant difference $(p>0.05)$ between the percentage hatchability of the beetle on all the food hosts. As evidenced by the larvae emergence data, cocoa $(4.28 \%)$ and groundnut $(5.42 \%)$ suffered significantly higher $(\mathrm{p}<0.05)$ levels of damage. However, based on the Kaplan Meier survival index $\left(P_{x}\right)$, it was noted that the adult enclosion and survival of the beetle was lowest on cocoa (0.27) and highest in cowpea (0.64). General Linear Model (GLM) revealed highly significant influence $(\mathrm{p}<0.0001)$ of food substrate $(S)$ on the fecundity of C. hemipterus $\left(\mathrm{F}_{3,320}=464.099\right)$ and its larvae development $\left(\mathrm{F}_{3,199}=345.042\right)$. It also showed the effect of Period $(\mathrm{P})$ on number of eggs $\left(\mathrm{F}_{3,320}=320.932\right)$ and larvae development $\left(F_{3,199}=188.167\right)$ to be highly significant $(p<0.001)$. Likewise, there was significant impact $(\mathrm{p}<0.0001)$ of the interaction of food substrate $x$ duration $(\mathrm{S} x \mathrm{D})$ on the oviposition of C. hemipterus $\quad\left(\mathrm{F}_{9,199}=5.167\right) \quad$ and larvae development $\left(\mathrm{F}_{9,199}=13.403\right)$. The ability of $C$. hemipterus to survive on less preferred food hosts is highlighted in this study.
\end{abstract}

Keywords: Carpophilus hemipterus; Enclosion; Hatchability; Survival.
Received

January 13, 2018

Accepted

April 02, 2018

Released

April 30, 2018

Full Text Article

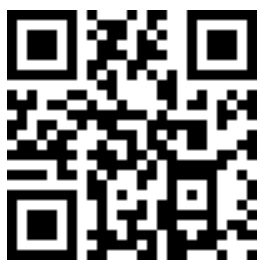

ORCID

(D) 0000-0001-8312-7012

Seun Olaitan Oladipupo

0000-0002-0604-6064 Chris Oluwakayode Adedire

(D) 0000-0002-2988-5223 Olahire Ayo Gbaye 


\section{Introduction}

The dried fruit beetle Carpophilus hemipterus (Linnaeus, 1758) (Coleoptera: Nitidulidae), is a serious cosmopolitan pest of dried fruits or insufficiently dried commodities (Haines, 1991; Gbaye and Odeyemi, 2005). Because of their dependence on moisture, Carpophilus spp are often indicators of inadequate drying or even mouldy conditions in stores (Haines, 1991). The nitidulid occurrence has been reported on stored beans, cocoa beans, oats, groundnut, spices and drugs (Patrick, 1987; Gbaye and Odeyemi, 2005). However, it occur much less on cereals and oil seeds. Damage to commodities is incurred by the feeding activities of the adult beetles and larvae on the flesh of dried fruits and on any moulds or yeast present there on (Gbaye, 2003) coalescing into direct and indirect damage (Burks and Johnson, 2012).

In studying the biology of economically important insect pests, one of the ultimate objectives is to estimate the rate at which the pest population will grow. Fecundity and enclosability, inter alia, are key components in the determination of the survival potential of a species (Southwood, 1978). Few studies have been conducted on C. hemipterus incidence and abundance on a number of hosts (Bartelt et al., 1992; James et al., 1997). The beetle's preference for some food materials was investigated by Bartelt et al. (1990) and it was reported that $C$. hemipterus preferred ripening and dried fruits. Gerling et al. (1981) reported that the quality of food medium helps an insect to develop successfully and dictates the developmental strategies. The roles of pheromones and food volatiles on C. hemipterus preference have also been explored (Bartelt et al., 1992). Nonetheless, there is not enough information on the biology and life history of $C$. hemipterus in relation to tropical food types. More so, because of the relatively wide spectrum of the host products that this insect is endeared to, it is therefore desirable to investigate the ability of this beetle to develop on alternate tropical hosts with a view of revealing its survival propensity.

Thus, this study evaluated the fecundity and survival rate of C. hempterus on some alternative tropical hosts. In that regard, this study assessed some aspects of the developmental biology of $C$. hemipterus with reference to the relationship between oviposition, hatchability, enclosability and survival. It also investigated host suitability for the insect with respect to four stored products namely, cocoa, cowpea, groundnut and rice.

\section{Materials and methods}

\section{Insect culture and maintenance}

Adult $C$. hemipterus used for this study were obtained from stock cultures in the Insectary Section of the Department of Biology, Federal University of Technology, Akure, Nigeria, and maintained under ambient temperature of $28{ }^{\circ} \mathrm{C} \pm 3{ }^{\circ} \mathrm{C}$ and relative humidity of $75 \% \pm 5 \%$. Cocoa seeds were purchased from farmers within Akure Metropolis. The seeds were cleaned and disinfested in a freezer for three days to kill any prior infestation by insects. The disinfested cocoa beans were thawed and placed in Kilner jars (3 L) containing some moist soil (to aid pupation) and adult $C$. hemipterus were introduced into the jars. The soil was kept moist for continuous availability of the dried fruit beetle throughout the period of the study.

\section{Moisture content determination of oviposition media}

$50 \mathrm{~g}$ of each food substrate (i.e. groundnut, cocoa, cowpea or rice) was pounded into powder with pestle and mortar. $2 \mathrm{~g}$ of the ground food was measured onto a filter paper and placed in the moisture analyzer. The moisture value displayed was read and recorded. 
The procedure was carried out separately and repeated three times for each of the food substrate.

\section{Effect of alternative hosts on oviposition of $C$. hemipterus}

A no choice experimental set up was used for this experiment. $50 \mathrm{~g}$ of each food substrate was measured into separate disposable plastic jars $(100 \mathrm{~mm}$ $\mathrm{x} 15 \mathrm{~mm}$ ) containing moist soil. Two freshly emerged copulating pairs of adult C. hemipterus from the stock culture were introduced into each food type. The covers of the plastic jars were perforated and the hole covered with muslin cloth which allowed for proper ventilation of the culture. The soil was kept moist throughout the period of study. The set up was monitored for four days and the number of eggs laid were counted and recorded on a daily basis. The copulatory pairs were then removed from the jars.

\section{Suitability of alternative hosts on the survival of $C$. hemipterus}

The oviposition jars were monitored for another 30 days. Numbers of emerging larvae were counted at interval of four days. At the end of the experiment, number of adults that emerged and final weight of the food substrates were recorded. The set up was replicated four times for each food.

\section{Statistical analysis}

The weight loss data obtained was correlated with number of adults using Microsoft Excel Software. The percentage hatchability, enclosability, survival and weight loss data were computed using the following formulae:

$$
\begin{aligned}
& \% \text { Hatchability }=\frac{\text { Total larvae }}{\text { Total egg laid }} \times \frac{100}{1} \\
& \% \text { Enclosability }=\frac{\text { Number of adult emerged }}{\text { Total larvae }} \times \frac{100}{1} \\
& \% \text { Survival }=\frac{\text { Number of adult emerged }}{\text { Total egg laid }} \times \frac{100}{1} \\
& \% \text { Weight loss }=\frac{\text { Initial weight loss }- \text { Final weight loss }}{\text { Initial weight loss }} \times \frac{100}{1}
\end{aligned}
$$

The oviposition and emerging larvae data were subjected to analysis of variance (ANOVA) at 95\% confidence interval, where significant difference occurred, the means were separated using Tukey's test. The separate and interactive effect of food substrate and duration was also determined using General Linear Model (GLM). The relationship between the food hosts weight loss data and adult emergence was also computed using regression analysis. In addition, Kaplan-Meier analysis was used to investigate the survival of $C$. hemipterus on the food substrates. All analyses were done with
Statistical Package for Social Sciences (SPSS), version 20.

\section{Results}

\section{Moisture determination of oviposition media \\ content}

The percentage moisture content of the alternate hosts tested is presented in Table 1. The lowest percentage moisture content was observed in rice $(11.00 \%)$. This moisture value was significantly lower $(\mathrm{p}<0.05)$ than those obtained on cocoa, groundnut and cowpea. 
Table 1. Moisture content (\%) of alternative hosts used for C. hemipterus rearing.

\begin{tabular}{lc}
\hline Substrate & Moisture content (\%) \\
\hline Cocoa & $13.66^{\mathrm{c}} \pm 0.09$ \\
Rice & $11.00^{\mathrm{a}} \pm 1.16$ \\
Groundnut & $14.00^{\mathrm{c}} \pm 0.58$ \\
Cowpea & $11.67^{\mathrm{b}} \pm 0.02$ \\
\hline
\end{tabular}

Values presented are mean \pm standard error (S.E.) of four replicates. Means followed by same alphabet in same column are not significantly different at $\mathrm{p}>0.05$ using Tukey's test.

\section{Effect of alternative hosts on oviposition of Carpophilus hemipterus}

The mean fecundity of C. hemipterus on alternate hosts at different periods is shown in Table 2 . The highest number of eggs of was recorded on groundnut (7.00) after $24 \mathrm{~h}$, this value was however not significantly higher $(p>0.05)$ than the quantity laid on cocoa (5.00) and cowpea (6.25) for the same period. Generally, significantly higher $(p<0.05)$ number of eggs were laid on groundnut than the other foods after $72 \mathrm{~h}$ and $96 \mathrm{~h}$. The lowest numbers of eggs were deposited on rice across all the intervals. These values were significantly lower $(\mathrm{p}<0.05)$ than those deposited on the other food substrates. General Linear Model (GLM) revealed highly significant effect ( $\mathrm{p}<0.0001)$ of food substrate (S) $\left(\mathrm{F}_{3,320}=464.099\right)$ and duration (D) $\left(\mathrm{F}_{3,320}=320.932\right)$ of oviposition on the fecundity of $C$. hemipterus. Likewise, there was significant impact ( $p<0.0001)$ of the interaction of food substrate $x$ duration (S $x$ D) on the oviposition of C. hemipterus $\left(\mathrm{F}_{9,199}=5.403\right)$.

Table 2. Effect of alternive hosts on oviposition of $C$. hemipterus.

\begin{tabular}{lcccc}
\hline \multirow{2}{*}{ Substrate } & $\mathbf{4}$ & \multicolumn{3}{c}{ Duration (h) } \\
\hline Cocoa & $5.00^{\mathrm{ab}} \pm 0.41$ & $10.00^{\mathrm{b}} \pm 0.91$ & $15.00^{\mathrm{bc}} \pm 0.91$ & $\mathbf{9 6}$ \\
Rice & $0.75^{\mathrm{a}} \pm 0.75$ & $2.00^{\mathrm{a}} \pm 1.22$ & $3.75^{\mathrm{a}} \pm 2.17$ & $4.25^{\mathrm{c}} \pm 0.85$ \\
Groundnut & $7.00^{\mathrm{b}} \pm 0.91$ & $12.25^{\mathrm{b}} \pm 0.85$ & $17.25^{\mathrm{a}} \pm 0.48$ & $23.50^{\mathrm{c}} \pm 1.04$ \\
Cowpea & $6.25^{\mathrm{b}} \pm 1.80$ & $8.5^{\mathrm{b}} \pm 1.55$ & $10.25^{\mathrm{b}} \pm 1.44$ & $11.75^{\mathrm{b}} \pm 0.85$ \\
\hline
\end{tabular}

Values presented are mean number of eggs deposited \pm Standard error (S.E.) of four replicates. Means followed by same alphabet in same column are not significantly different at $\mathrm{p}>0.05$, using Tukey's test.

\section{Effect of alternative hosts on the larvae population of $C$. hemipterus}

The mean number of larvae of C. hemipterus that emerged on the alternative hosts at different periods is shown in Table 3. At day 8, the highest number of larvae was recorded on cocoa (5.75) and groundnut (5.75) and the lowest in rice $(0.75)$. This trend was generally observed between cocoa and groundnut, there was no significant difference $(p>0.05)$ between numbers of larvae found on the two hosts at every interval. However, the populations of larvae on these two hosts were significantly higher $(\mathrm{p}<0.05)$ than those recorded on cowpea. General Linear Model (GLM) revealed highly significant effect ( $p<0.0001$ ) of food substrate (S) on the development of $C$. hemipterus larvae on alternative hosts $\left(F_{3,199}=345.042\right)$. It also showed the 
effect of duration (D) on the larvae population to be highly significant $\left(\mathrm{F}_{3,199}=188.167, \quad \mathrm{P}<0.001\right)$. Likewise, there was significant impact $(\mathrm{p}=0.004)$ of the interaction of food substrate $x$ duration $(\mathrm{S} x \mathrm{D})$ on the larvae development of C.hemipterus $\left(\mathrm{F}_{3,199}=13.403\right)$.

Table 3. Effect of alternative hosts on C. hemipterus larvae population.

\begin{tabular}{lccrr}
\hline Substrate & \multicolumn{4}{c}{ Duration (Days) } \\
& $\mathbf{8}$ & $\mathbf{1 2}$ & \multicolumn{1}{c}{$\mathbf{1 6}$} & \multicolumn{1}{c}{$\mathbf{2 0}$} \\
\hline Cocoa & $5.75^{\mathrm{c}} \pm 0.48$ & $8.00^{\mathrm{b}} \pm 0.41$ & $12.25^{\mathrm{b}} \pm 0.85$ & $16.25^{\mathrm{b}} \pm 1.44$ \\
Rice & $0.75^{\mathrm{a}} \pm 0.48$ & $1.50^{\mathrm{a}} \pm 0.87$ & $2.00^{\mathrm{a}} \pm 1.22$ & $3.25^{\mathrm{a}} \pm 1.88$ \\
Groundnut & $5.75^{\mathrm{c}} \pm 0.85$ & $9.50^{\mathrm{b}} \pm 0.65$ & $13.75^{\mathrm{b}} \pm 0.75$ & $17.25^{\mathrm{b}} \pm 0.63$ \\
Cowpea & $1.50^{\mathrm{b}} \pm 0.65$ & $3.25^{\mathrm{a}} \pm 0.85$ & $5.75^{\mathrm{a}} \pm 1.11$ & $8.50^{\mathrm{a}} \pm 1.71$ \\
\hline
\end{tabular}

Values presented are mean number of larvae \pm standard error (S. E.) of four replicates. Means followed by same alphabet in same column are not significantly different at $p>0.05$ using Tukey's test.

\section{Effect of food substrates on the survival of $C$. hemipterus}

The percentage hatchability and enclosability of $C$. hemipterus on the alternative hosts are presented in Figure 1. Generally, regardless of the total number of eggs initially laid, there seems to be little difference between the hatchability rates recorded on the food hosts (cocoa, 76.67\%; rice $76.47 \%$; groundnut $73.40 \%$; and cowpea $72.34 \%$ ). The enclosability data (Figure 1) showed that the highest percentage of larvae reached the adult stage on cowpea
(88.24\%), while the lowest was recorded on cocoa (43.08\%). The enclosability values on rice and groundnut were not significantly different $(p>0.05)$ from each other. Though the highest number of adult emerged from groundnut (Figure 2), the highest survival rate of the dried fruit beetle progeny was recorded according to our result on the survivability index value $\mathrm{p}_{\mathrm{x}}$, the survivability of $C$. hemipterus was more pronounced on cowpea with survival index $\left(\mathrm{P}_{\mathrm{x}}\right)$ of 0.64 (Table 4). The lowest survival index was recorded in cocoa $\left(P_{x}=0.27\right)$.

Table 4. Kaplan-Meier survival table for the survival of $C$. hemipterus on good substrates.

\begin{tabular}{lccccc}
\hline $\mathbf{X}$ & $\mathbf{I}_{\mathbf{x}}$ & $\mathbf{d}_{\mathbf{x}}$ & $\mathbf{q}_{\mathbf{x}}$ & $\mathbf{p}_{\mathbf{x}}$ & $\mathbf{P}_{\mathbf{x}}$ \\
\hline Cocoa & 85 & 62 & 0.73 & 0.27 & 0.76 \\
Rice & 17 & 8 & 0.47 & 0.53 & 0.14 \\
Groundnut & 94 & 47 & 0.50 & 0.50 & 0.26 \\
Cowpea & 47 & 17 & 0.36 & 0.64 & 0.32
\end{tabular}

$X=$ food substrate; $I_{x}=\#$ alive at the time; $d_{x}=$ \# who died at the time; $q_{x}=$ proportion who died; $p_{x}$ $=$ proportion survived; $\mathrm{P}_{\mathrm{x}}=$ cumulative proportion surviving on food substrate. 


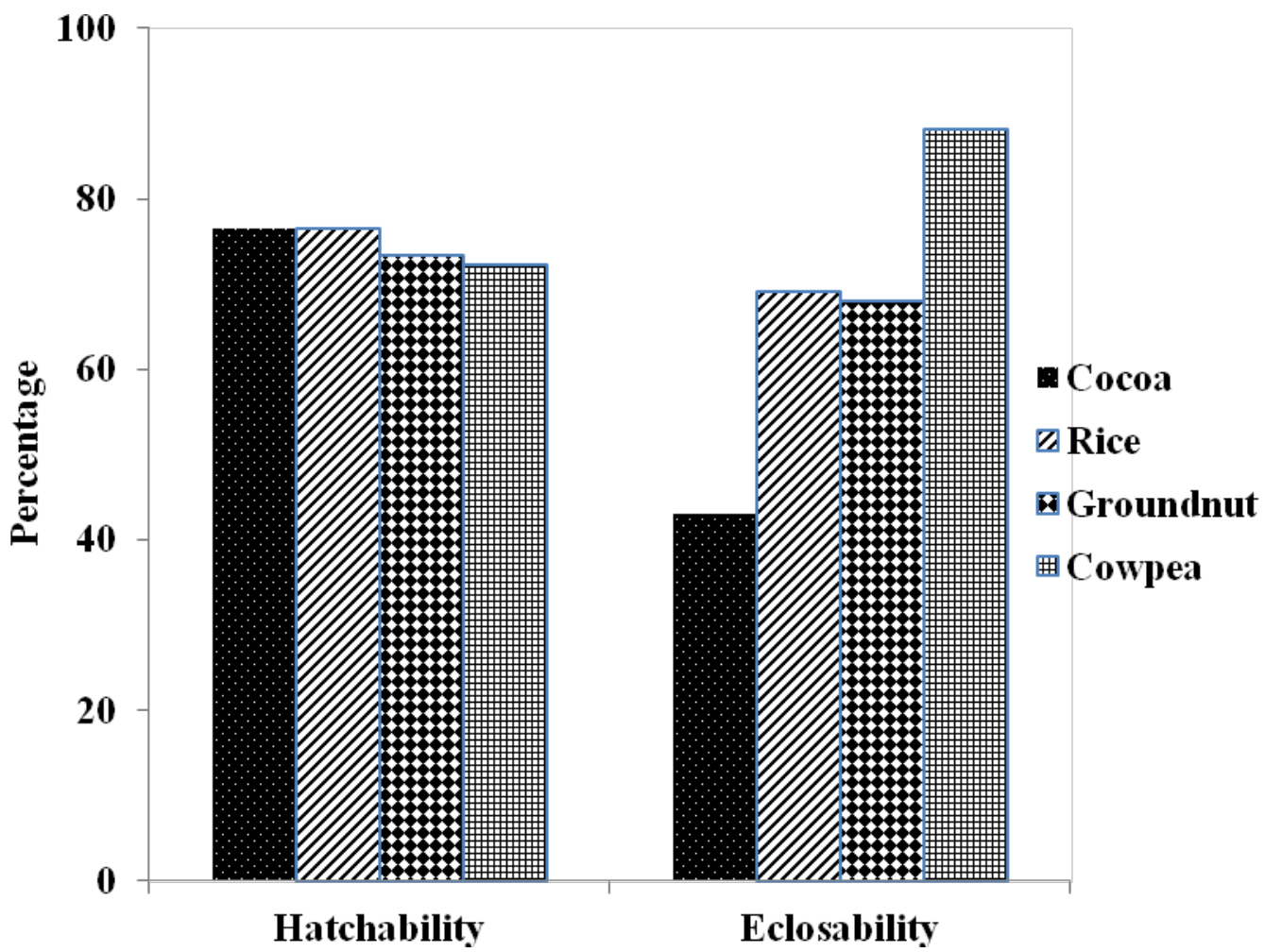

Figure 1. Effect of food substrates on the survival of $C$. hemipterus.

Effect of $C$. hemipterus adult emergence on weight loss of alternative hosts

The mean number of adult nitidulids that emerged on each food host was correlated with the weight loss data (Figure 2). Regression analysis showed that the higher the number of emerged adult, the higher the weight loss $(\mathrm{R}=0.7459)$, this was used as an indices of host damage. Expectedly, the greatest damage $\quad(5.42 \%$ weight loss $)$ was observed on groundnut, the food host with the highest number of adults (11.75). In the same light, rice, with the lowest mean counts of adult (2.25) suffered the least damage $(0.29 \%$ weight loss). Surprisingly, cowpea recorded higher mean adult count (7.50) than cocoa (5.75), however cocoa suffered more damage (4.28\% weight loss) than cowpea (2.92\%). 


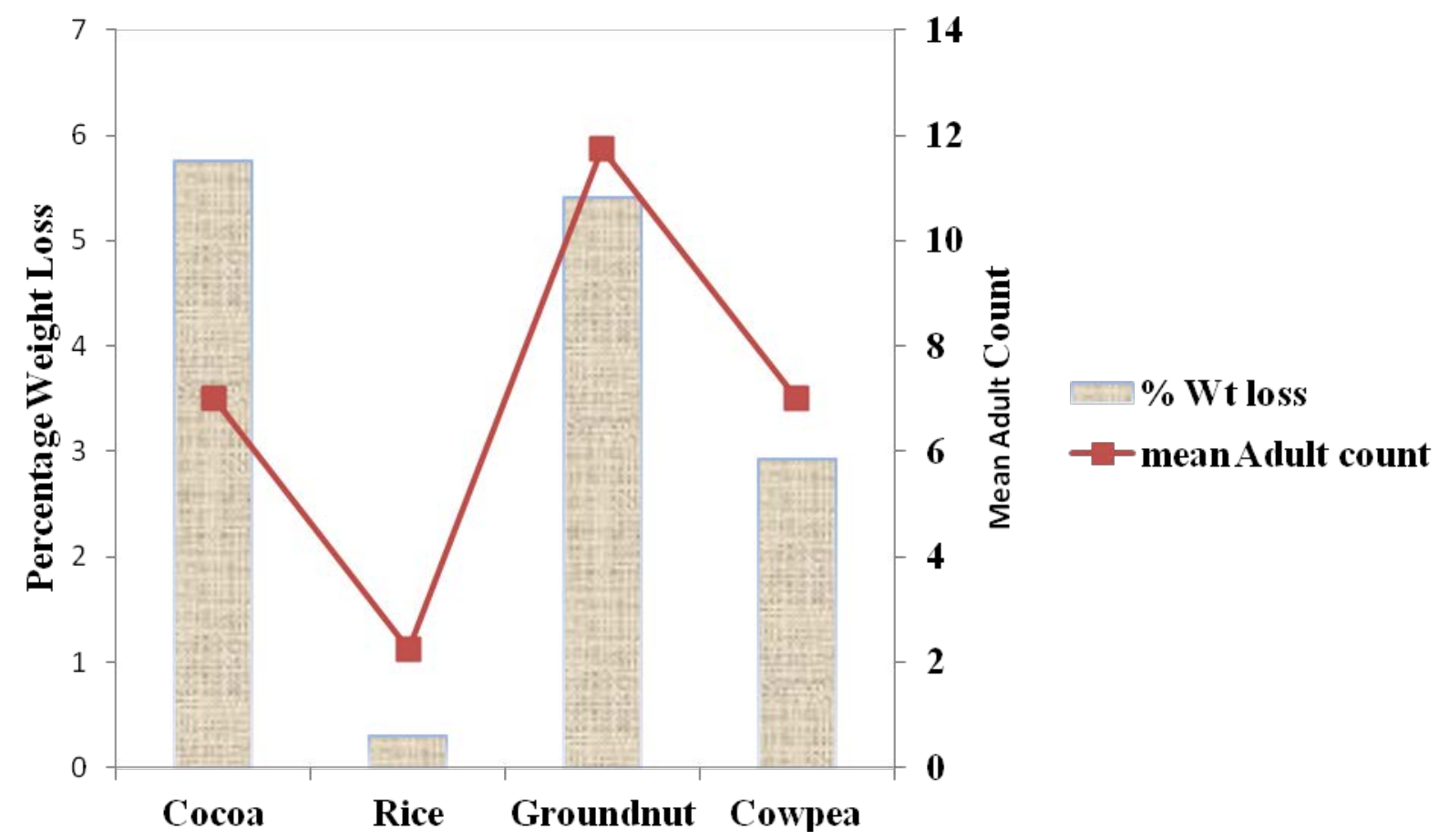

Figure 2. Effect of $C$. hemipterus adult emergence on weight loss of food hosts.

\section{Discussion}

The observed results in this study provide information on the relationship between the innate ability of the female $C$. hemipterus to know the suitability of a substrate for the development and survival of its progeny. The study showed that cocoa and groundnut encouraged the fecundity of C. hemipterus more than rice and cowpea. This could be due to the higher moisture content recorded in the former hosts. This is in agreement with the report that C. hemipterus prefers food substrates with high moisture content (Johnson, 1987). The lower fecundity observed in rice and cowpea might probably be as a result of the hardness of these grains as well as the low moisture content value exhibited by both food hosts (Singh, 2002).

Although fewer eggs were deposited on rice when compared to other hosts in a no choice experimental set up, there was little variation in the percentage hatchability observed. That is, though fewer eggs were laid on rice, the proportion that hatched was the same with that of cocoa on which fecundity was higher. Hence, this could indicate that should the beetle proliferate on this less prefered food material (rice), it could become a major problem. The concern with this is that in Nigeria for instance, food items are indiscriminately stored together, hence, rice could become an harbour for C. hemipterus in the absence of a preferred host. The implication is that rice could keep the generations of the beetle alive when conditions become unfavourable. Even in unfavourable conditions, the populations will remain unchecked.

It was observed that the survival rate of $C$. hemipterus on cocoa was the lowest taking into cognizance the proportion of eggs laid on it vis-a-viz the emerged adult. The diverse survival rates observed in this study could be linked to the different food types investigated. Toxic and antinutritional compounds encountered in plants by insects differs 
from food to food. Cocoa contains different alkaloids including tannin, this can hamper $C$. hemipterus larvae development on this host due to their inability to optimally utilize the various food component therein. Gbaye and Holloway (2011) postulated that tannin is a polyphenol which protects plants from insect attack by forming complexes with food components, hence reducing effective utilization of such component to generate energy leading to starvation of such herbivore.

Food-loss assessments provide the basis of programmes for reducing postharvest losses. In this study, the weight losses of the food substrates were measured as an index for damage. It was discovered that groundnut supported the highest adult emergence and suffered the greatest damage by the dried fruit beetle. Although, both groundnut and cocoa attracted more eggs, but significantly higher number of adults emerged from groundnut. However unlike cocoa, groundnut, though a legume with antinutritional factors (Harborne, 1988), still support the development of C. hemipterus. Thus, this indicates that groundnut may be a good host for the survival of this insect. It is worthy of note that both cocoa and groundnut have high lipid and phytochemical content (Harborne, 1988; Andujar et al., 2012), nevertheless, the diverse factors in them that had contrary impact on C. hemipterus survival needs further investigation. Equally cowpea, the host with the highest survival index for C.hemipterus, is also a legume with antinutritional factors like groundnut. It has less lipid content and moisture content than both cocoa and groundnut, conversely, the inherent ability of the progeny of this nitidulid to survive on groundnut might have aided its survival on cowpea. The ability of $C$. hemipterus larvae to deal with diverse phytochemicals (including alkaloids and protein inhibitors) in legumes is an indicator that this species possesses a good enzymatic detoxification ability worthy of investigation. Such detoxification mechanism might confer on it the ability to tolerate xenobiotics which might be used for its control (Gbaye et al., 2012). Again, the quantity of alkaloid in cocoa and the types therein might be too much for this nitidulid to deal with, this is also open to confirmation.

Generally, there is paucity of information on the biology of C. hemipterus, its activities on alternative hosts, among all other things, highlight the innate ability of the insect to know the suitability of a substrate for the development of its progeny. This might give a cue on the tendency of development of $C$. hemipterus on an alternative hosts, however this does not preclude a low survival rate on such host. Adverse conditions such as low moisture content and hardness of food substrates could reduce the fecundity of C. hemipterus. During control, storage facility operators having diverse food hosts in proximity need to note the inherent ability in C. hemipterus to survive on legumes vis-à-vis the probable xenobiotic tolerant ability they (legumes) might confer on it.

\section{Conclusions}

The ability of $C$. hemipterus to survive on less preferred food hosts in the absence of its conventional host was highlighted in this study.

\section{Conflict of interest statement}

The authors declare that they have no conflict of interest.

\section{Refrences}

Andujar, I.; Recio, M. C.; Giner, R. M.; Ríos, J. L. Cocoa polyphenols and their potential benefits for human health. Oxidative Medicine and Cellular Longevity, v. 2012, Article ID 906252, p. 1-23, 2012. https://doi.org/10.1155/2012/906252 
Bartelt, R. J.; Dowd, P. F.; Plattner, R. D.; Weisleder. D. Aggregation pheromone of driedfruit beetle, Carpophilus hemipterus: wind-tunnel bioassay and identification of two novel tetraene hydrocarbons. Journal of Chemical Ecology, v. 16, p. 1015-1039, 1990. Bartelt, R. J.; Weisleder, D.; Dowd, P. F.; Plattner, R. D. Male-specific tetraene and triene hydrocarbons of Carpophilus hemipterus: Structure and pheromonal activity. Journal of Chemical Ecology, v. 18, p. 379-402, 1992.

Burks, C. S.; Johnson, J. A. Biology, behavior, and ecology of stored fruit and nut insects. In: Hagstrum, D. W.; Phillips, T. W.; Cuperus, G. (Eds.). Stored product protection. Kansas: K-State Research and Extension, 2012. p. 21-32.

Dowd, P. F. A labor saving method for rearing the driedfruit beetle (Coleoptera: Nitidulidae) on pinto bean-based diet. Journal of Economic Entomology, v. 80, no. 6, p. 1351-1353, 1987. https://doi.org/ 10.1093/jee/80.6.1351

Gbaye, O.A. The use of controlled atmosphere for the control of Carpophilus spp. (Coleoptera: Nitidulidae) and Drosophila melanogaster (Meigen) (Diptera: Drosophilidae). Akure: Federal University of Technology, 2003. (Master Dissertation)

Gbaye, O. A.; Holloway, G. J; Callaghan, A. Variation in the sensitivity of Callosobruchus (Coleoptera: Bruchidae) acetylcholinesterase to the organophosphate insecticide malaoxon: effect of species, geographical strain and food type. Pest Management Science, v. 68, no. 9, p. 1265-1271, 2012. https://doi.org/10.1002/ps.3293

Gbaye, 0. A.; Odeyemi, 0. 0. Evaluation of hypercarbia atmosphere on the mortality of dried-fruit beetle, Carpophilus hemipterus (Linnaeus). Journal of Food, Agriculture \& Environment, v. 3, no. 3/4, p. 43-46, 2005.

Gerling, D.; Hurd, P. D.; Hefetz, A. In-nest behavior of the carpenter bee, Xylocopa pubescens Spinola (Hymenoptera: Anthophoridae). Journal of the Kansas Entomological Society, v. 54, no. 2, p. 209-218, 1981.
Haines, C. P. Insects and arachnids of tropical stored products: Their biology and identification (a training manual). Chatham, U.K.: Natural Resources Institute, 1991.

Harborne, J. B. Introduction to ecological biochemistry. London, UK: Academic Press, 1988.

James, D. G.; Faulder, R. J.; Vogele, B.; Bartelt, R. J.; Moore, C. J. Phenology of Carpophilus spp. (Coleoptera: Nitidulidae) in stone fruit orchards as determined by pheromonetrapping: Implications for prediction of crop damage. Austral Entomology, v. 36, no. 2, p. $165-173$, 1997. https://doi.org/10.1111/ j.1440-6055.1997.tb01450.x

Johnson, J. A. Sensitivity of larvae, pupae and adults of the dried fruit beetle (Coleoptera: Nitidulidae) to gamma radiation. Journal of Economic Entomology, v. 80, no. 6, p. 1302-1305, 1987. https://doi.org/ 10.1093/jee/80.6.1302

Leftovitch, L. P. Some observations of the life cycle of Carpohilus dimidatus (F) (Coleoptera: Nikidilidae) on wheat bran. Journal of Stored Products Research, v. 2, no. 2, p. $163-165$, 1966. https://doi.org/10.1016/ 0022-474X(66)90021-X

Patrick, F. A Labor-saving method for rearing the driedfruit beetle (Coleoptera: Nitidulidae) on Pinto Bean-Based Diet. Journal of Economic Entomology, v. 80, no. 6, p.1351-1353, 1987. https://doi.org/ 10.1093/jee/80.6.1351

Singh, B. B. Recent genetic studies in cowpea. In: Fatokun, C. A.; Tarawali, S. A.; Singh, B. B.; Kormawa, P. M.; Tamo, M. (Eds.). Challenges and opportunities for enhancing sustainable cowpea production. Ibadan, Nigeria: International Institute of Tropical Agriculture, 2002. p. 3-13.

License information: This is an open-access article distributed under the terms of the Creative Commons Attribution License, which permits unrestricted use, distribution, and reproduction in any medium, provided the original work is properly cited. 